\title{
Performance Appraisal-Management by Objective and Assessment Centre-Modern Approaches to Performance Appraisal
}

\author{
Brijesh Goswami ${ }^{1}$, Dr. Mamta Sharma ${ }^{1}$, Dr. Sujata ${ }^{2}$ \\ ${ }^{I}$ Department of Humanitites, Hindustan College of Science and Technology, Farah Mathura \\ ${ }^{2}$ Department of English, Manav Rachana International University, Faridabad
}

\begin{abstract}
Problem statement: Performance appraisal is a crucial activity of HR department in any organization. Employees are appraised for several reasons, not only for reward and punishment but much more than. Most important of which is to realize the best use of human resources and to plan for future needs Two methods for performance appraisal that are discussed in this study are Management By Objective (MBO) and Assessment Centre techniques. Assessment Centre evaluation or Management by Objective is valuable because it allows a candidate to concentrate on the task at hand.

Approach: The literature review and arguments were conducted to provide a systematic discussion of the study. Results: In Assessment Centre Appraisal, the different outcomes for particular tasks can be evaluated and management can assess employee's relative proficiencies in terms of these tasks. In MBO, employees are obliged to deal with overcoming challenges. $M B O$ and Assessment both require consistency in criteria for comparison and standardization.

Conclusion: Difference organizational culture and motives for appraisal have an impact on result of both the appraisal methods. Outcomes of tasks given for assessment may different and involve different level of risks. In assessment center method employee is separated from others to appraise his performance. At times Management by Objective is effective method for comparison and judging employee performance in changing environment.
\end{abstract}

Key words: assessment centre, management by objective, punishment, performance appraisal, reward.

\section{INTRODUCTION}

In any organization there is need of high performance \& to bring out the hidden potential of workers to active level. Performance Management is crucial part of HR activities in organization. Managers often believe that the most significant HR outcome involve the contributions that employees make to organization is goal attainment. These contributions are called Performance, meaning how effectively employees carry out these job responsibilities (Heneman). Performance can be formal or informal It is the responsibility of supervisor to determine how effectively their subordinates are performing different tasks allotted to them in their respective positions, to identify and to correct their weak points \& to recommend them on the basis of their potentialities for promotions to higher position in organizations. One of the pre-eminent purposes of appraisals is to positively affect future performance (Cleveland, Murphy \& Williams 1989; Huffman \& Cain 2000; Swanson \& Holton 2001; Thomas \& Bretz 1994). As Latham, et al. (1993), state the basic purpose of conducting PAs is to improve the performance of the affected employees. The PA purposes like communication of super-ordinate goals, the capacity of PA to increase employees' perceptions of being valued and being part of an organizational team (Levy \& Williams 2004). Sometimes employees are overvalued or undervalued which depends upon the method of appraisal. In some organizations informal appraisal also exists. It is a social interaction. We all appraise each other.

Appraisal system is used to reinforce productivity and quality efforts. There are different criteria to perform a job \& these criteria may vary from organization to organization, level to level \& function to function (Reddin).A good appraisal programme results in fairer evaluations that are effective in terms of human recourses so allow in wise allocation of these resources. An appraisal system is likely to be an utter failure if it lacks the support top management to take decisions regarding Performance appraisal are discussed. In this study Management by Objective and Assessment center methods are discussed.

\section{APPROACH}

The literature review and arguments were conducted to provide a systematic discussion of the study about Management by Objective and Assessment Center. 


\section{WHY APPRAISALS ARE DONE}

Every employee perceives objective of Performance Appraisal in different ways. Some consider appraisal only for rewards and some consider it threatening of penalty and demotions. Employees are appraised for several reasons other than rewards and punishments. Objective of this programme is to improve the efficiency of an enterprise by attempting to mobilize the best possible efforts from the individuals employed in organizations (Cumming).Appraisals are valuable in deciding on promotions and raises and even on the occasion for deciding who will be kept on the pay roll and who will be dismissed. But they are not conducted primarily for any of these reasons. The primary purpose is to help each man to handle his job better (Rowland).

Performance appraisal also exerts motivational impact on individuals, strengthens their initiative, promotes a sense of responsibility in them and enhances their efforts towards organization goals. With a proper performance appraisal process, organizations inform their employees about the standards of organization and improve the consistency of employees. Performance appraisal is likely to provide the individuals improved understanding of job responsibility, relationships with other functions expected in their roles and training requirements. It also assists superiors to understand their subordinate's work behavior, work itself and individual's strengths and weaknesses to develop the teamwork in organizations and bring organization productivity at optimum level. Performance Appraisal System provides for Organization's effective measure for assessing how much salary increment should be given, salary fixation and is an effective tool to justify demotions, dismissal or other corrective action. Performance Appraisal helps organization to achieve goals by staff development $\&$ improved communication, as it not only finds the training needs but also discovers the hidden talents of individuals.

\section{ASSESSMENT CENTRE APPRAISAL VS. MBO}

Both the tools of Performance Appraisal - MBO and Assessment Centre are important and useful but as every activity have some pro and cons, both methods have some drawbacks too. Management has to decide which method is to be chosen or preferred over another. Decision of the method depends upon various factors such as organisational climate especially management style, technology and Quality of subordinates (Diwedi). MBO and Assessment Centre both are result oriented approaches. MBO is a system wherein the superior \& subordinate of an organization jointly define its common goals, define each individual's major area of result expected of him and use of these measure as guides for operating the unit $\&$ assessing the contribution of each member (Odiorne). Assessment centre method does much more than merely testing individuals; it is a process by which an individual potential is assessed for managerial positions on the basis of three sources, i.e. multiple assessment technique including situational tests, test of mental ability \&interest inventories, Standardized method of making inferences, Pooled judgments from varied evaluator to rate each individual's behavior (Cascio). Assessment center has become widely used in organizations as a tool to select $\&$ develop leadership talent. (Krajewski).

The popularity of the assessment center is largely due to consistent evidence of its criterion-related validity (Arthur). Assessment Centre evaluation or appraisal allows a candidate to concentrate on the task at hand. Distractions can be minimized and real proficiency or potential can be seen in play, in regard to a particular task. Evaluator can judge the achievement levels \& compare performance with other. In Assessment center, arrangement can be done according to requirements. Further, the monitor can come to understand any impediments that affect the individual candidate and devise strategies for overcoming them. In an empirical setting, rather than the clinical setting of the workplace, such in depth personal evaluation may not be possible. On the other hand, assessment centers have major disadvantage that it does not reflect the abilities of individuals in real circumstances of workplace. In Management by Objective performance appraisal, employees are obliged to deal with overcoming empirical challenges. In most non-clinical scenarios, employees will not be able to concentrate on single tasks at any given time. This incapacity is increasingly apparent, the higher up an organizational pyramid a candidate is, whether as an expert or manager. The more informed the employee is, or the more pivotal is his or her position, the more likely it is that demands will be made by other members of the organization to help solve problems or make decisions in a number of areas, or give authority or advice concerning several matters.

\section{ENVIRONMENT, EMPLOYEE AND COST OF APPRAISAL}

Performance appraisal incurs some cost as every activity does. In regard to the cost of appraisal, "A primary component of any useful or meaningful productivity improvement program is its measurement system. In the input/output analysis, the quality and quantity of human resources and their efforts are critical factors influencing productivity improvement". (Henderson,1980). Such improvement may be contingent on improving the workplace either in terms of physical environment or behavior and morale or by providing incentives; in some cases, it may be requisite to introduce strategies or penalties to reduce shirking, which may account for the 
differences between results at an assessment centre and those provided through Management by Objectives. So even Performance appraisal bears the cost but it returns in the form of productivity, increasing morale and maximization of profits.

\section{SOCIAL AND EMPATHIC VIEWS}

MBO is an effective and useful tool to enhance the productivity level but MBO managers focus on the result, not the activity. They delegate tasks by "negotiating a contract of goals" with their subordinates without dictating a detailed roadmap for implementation. It focuses only on the tangible outcomes and ignores the intangible outcomes i.e. morale because it does not judge the every task and how employee tackles the routine daily problems and eventual difficulties as it is concerned only about final objectives. It also conceals poor performance, distortion of data $\&$ fixation of low goals. Productivity may seem high or low, it does not mean that employee has used every resource efficiently. It may be possible that favorable conditions helped him to achieve the targets and it is also possible his extra talent or extra efforts make him to overcome the difficulties to achieve the targets. But these difficulties or favorable conditions do not counterpart the appraisal in MBO. In Assessment Center there is simulation of environment not the real environment so it may possible that on one performing in assessment center will perform as effective in real situations and vice versa. In such situation where environment is important part of evolution comparative evolution plays important role.

\section{FLEXIBILITY OF ASSESSMENT CENTRE AND MBO}

Assessment center provides immense flexibility to users. Attempt may be made to tailor specific content and design of the centre to job characteristics for example for a managerial job. Assessment centre can be designed to predict how an individual is likely to behave in next higher level of job. It gives the projection over the current status to next higher level. On the other hand MBO focuse on the current job \& functions. MBO does not focus on the intermediate steps. It is concerned about the final results or outcomes i.e. goal achievement. It nourish the autonomy. Autonomy may be the most fundamental psychological needs (Sheldon). The employee in an MBO programme ideally has autonomy in the areas appraised so that the efficiency or inefficiency of other workers does not impact on the candidates' performance results. Where comparisons are made with other employees, the criteria need to be parallel for employees at similar levels of responsibility. It may be, for example, that some employees' efforts do not generate results in the short term; their efforts may be based over a longer time frame. It would be inappropriate to compare outcomes for this employee against one whose output is tied to daily or hourly performance schedules. Comparison should be made in single frame with similar work and environment.

\section{PREREQUISITES}

\section{Let your employees know about Appraisal:}

Performance management aims not only on the current performance, it is also concerned to bring out potential of employees to tangible performance. Where an employee knows that he or she is being assessed, then performance is likely to be optimized and in this way the monitor can realize the full realizable value of the employee as a human resource under ideal conditions, from the point of view of management (Nankervis, 1993). Employees often want feedback, but they are not given, especially at more senior levels; thus it is hard to realize the relative value of their performance compared to their peers and so cannot set in place plans for selfimprovement, other than on their own cognition. For example, "At the executive level, there is often almost no regular performance feedback other than superficial praise or criticism for some crisis." (Cascio, 2002). Whether $\mathrm{MBO}$ or assessment centre methodology is used can depend on the position held in an organizational hierarchy. In this case, where managers cannot be monitored or appraised in any depth because senior management lacks the time, or because no other senior member of staff has the expertise to make judgments about a fellow manager, MBO is unlikely to be appropriate or feasible. Management consultants, however, can devise assessment center strategies for advising such managers and so give them direction for self-improvement.

\section{Reliability:}

There must be reliability of results over time. With change in time there is change in different parameters like technology, economic factors, human resources or physical environment. They are not static for long time. When different forms of appraisal are not used to corroborate with each other, they each must meet a number of requirements. In MBO, the results need to be quantifiable in both the long and short term (Nankervis, 2002). Thus there is an in-built mechanism for comparison. Where results are graphed, upward spikes in performance or downturns can be seen in the context of the output and performance. The different outcomes for particular tasks can be evaluated and management can assess employee's relative proficiencies in terms of these 
tasks. But it can be difficult to implement $\mathrm{MBO}$ assessments in their ideal form because of the time frame logistics. (Nankervis,2002).

\section{Benchmarking:}

Effective performance appraisal requires the standards by which performance can be compared. Management will normally have some preferred methodology for achieving outcomes and because of the need to assess employees according to standardized criteria, then a standard procedure will be requisite for achieving predetermined outcomes. (Nankervis, 1993). Where these standards are used however, they may result in lower apparent efficiency if an employee normally uses alternative methods. If the outcomes realized in the MBO programme are lower than expected, then management could be well advised to review its approach to standardized expectations.

\section{RESULTS}

Complementary method to each other: It is clear that both forms of evaluation are viable and useful but often that ideally neither can stand-alone. Monitors who can set up clinical settings can provide rankings to employees in regard to particular tasks and technical knowledge in regard to effectiveness and problem solving. Later or consequent to having a range of outcomes for employees, comparisons and contrasts can be made relative to similarities and differences in proficiencies and outcomes. An overview of this type could lead to decisions and strategic devices for improving the performance of employees relative to potential, based on deeper and broader holistic perceptions by management.

Assessment center implies in-basket test, to test the candidate's priority to work; Leadership Group Discussions (LGD), Paper pencil test to evaluate intellectual ability, projective tests to assess work oriented motivation. Such activities indicate the candidate's ability to work in a team and programme thinking pattern of candidate which are important attributes of a manager.

Business games are also used in this context where candidates make decisions and have to accept the consequences of their decisions. If the candidate takes right decision, he or she will be rewarded by increased productivity and profits, as well opportunity for advancement in the firm. However, if the plan fails, because the new labor cannot or will not achieve the desired improvements in productivity, or if it demands a higher increase on its starting wage, or if it takes newly learned portable skills to another firm, then the candidate in the business game will be responsible. Alternately, because once the labor is trained without having been bound by a firm contract, it is too expensive to let them go and replace them, so higher wages than expected have to be paid. If the labor leaves and goes to another firm which does not have to bear the cost of training, then the candidate's firm can lose a competitive edge. The firm may fail, or the candidate in the business game may be denied further access to promotion or be dismissed.

These devices for assessment are all quite effective and provide insights, but they are based in hypotheses. The devices remain games. As such, they may give insights into intelligence and the levels of risk taking behavior likely in the candidate. Whether risk averse, risk neutral or risk loving employees are desirable can depend very much on organizational culture. Differences between organizational cultures will impact on the way that assessment results are received under MBO performance appraisal as well.

The outcomes that employees achieve in the tasks provided for appraisal purposes may involve different levels of risk, even within firm guidelines. The risk loving employee will advise on the upper limit and so expose the firm to a higher probability of success; the more risk adverse employee will recommend shares with the lower level of risk; such recommendations may expose the firm to accusations of inadequate business acumen. In an MBO setting, the actual results of decisions can be seen, while in assessment centre appraisal they can only be extrapolated. But in each case, it can still be difficult for a monitor to ascertain whether the candidate is appraised independently of the setting for the appraisal, whether it is the assessment center laboratory or the empirical workplace in a market setting, where real business and economic factors come into play (Basu and Datta, 2010)

In the interrelated jobs individual appraisal is difficult. In the assessment centre, the candidate is separated from colleagues. The assessment centre is also more likely to evaluate performance using clinically testing tools such as Behaviorally Anchored Rating Scales (BARS); Behavioral Observation Scales (BOS); and Behavioral Discrimination Scales (BDS). These tools can be applied over a longer time frame, as in an MBO context, (Campbell,1998) but the cost of monitoring is high, Even so, if the period over which these tools are used is limited to one or two days, short term myopia can affect the results.

MBO is useful for lower level tasks; where decision-making is not a major function of the job and have less effect on the major process. But beyond this level, MBO can lack opportunities for truly deep employee analysis, unless considerable time is given to setting up criteria for assessment (Chegini, 2010). To make comparative rating assessments, effective MBO will incorporate objective criteria. For example, "BARS use 
more objective, behavioral standards. The standard is a detailed description of observable behavior, such as submitting reports on time with no spelling, typing, or grammatical errors; writes clearly and succinctly" (Gordon, 1986).

\section{CONCLUSION}

Organisational performance is a comprehensive process meant to offer an overall understanding of the organization as a balanced structure, in which different aspects contribute synergistically to general performance (Ecaterrina, 2011) Performance appraisal is difficult but essential for a firm that need manage its human resources effectively in order to reduce costs and maximize profits (Al-Zhrani, 2010). Firms that want to maintain high morale will also ensure that their employees feel appreciated and motivated .The number of organizations using performance appraisals as a managerial tool necessary for facilitating the performance levels necessary to achieve the company's mission and strategies is on the increase (Carifio, 2010). Many companies are just now realizing what an effective tool a performance appraisal can be. They have begun to emphasize the correct use of performance appraisals in their organizations for the betterment of the company (Doleh and Weir, 2007). Employees are likely to be motivated to achieve such recognition. But the firm must have devices for ensuring accurate measurement that employees have confidence in and which allow the firm to make fair judgments regarding their use and future needs of human resources. Therefore it is essential that human resource managers know when to use appropriate types of evaluation (Olugu and Wong, 2009). MBO is useful. Where a firm has to make decisions between a small number of executives, within limits of the time and costs to evaluate them.. Assessment Centers, however, will be more suited to middle and senior staff, or where potential is more important than everyday practice, or where there is reason to believe that significant changes can be made to current inputs from human resources. In fact neither MBO nor assessment centre methodologies, then, can be categorized as superior. In some situations, one is preferred to the other, some other method might be optimal in some different situations. Management and experts will decide which method to use depending on context and circumstance.

\section{REFERENCES}

[1] Dwivedi, R.S., Managing human Resources, Personnel Management in Indian Enterprises. Galgotia Publishing Company, New Delhi, 2006

[2] Cumming, M.W., The theory and Practice of Personnel Management, London:William Heineman ltd. P. 111-112

[3] Heneman,H.G., Personnel/Human Resource Management, Universal Books, New Delhi.

[4] Reddin, W.J., Effective Management by Objective, New Delhi, Tata- Mcgraw Hill, New Delhi

[5] Odiorne,G, Management By Objective, New York, Pitman, p.55

[6] Murphy, K.R., \& Cleveland, J.N. . Performance Appraisal: An organisational perspective. Needham Heights, MA, Allyn \& Bacon. (1991)

[7] Huffman, C., \& Cain, L. B. . Effects of considering uncontrollable factors in sales force performance Evaluation. Psychology \& Marketing, 17 (9), 799-833, (2000)

[8] Latham, G. P., Skarlicki, D., Irvine, D., \& Siegel, J. P.. InC. L. Cooper \& J. T. Robertson. Eds. Vol.8, Chap.3, pp. 87-133. London: John Wiley \& Sons. (1993)

[9] Doleh, J. and D. Weir, Dimensions of performance appraisal systems in Jordanian private and public organizations. Int. J. Human Resource Management, 2007, p.75-84.

[10] Gordon, J.R., 1986. Human Resource Management: A Practical Approach. 1st Edn., Allyn and Bacon, Sydney, p. 771.

[11] Krajewski, H., R. Goffin, M. Rothstein and N. Johnston, 2007. Is Personality related to assessment center performance? That depends on how old you are. J. Bus. Psychol., p. 21-33.

[12] Nankervis, A.R., R.L. Compton and T.E. McCarthy, 2002. Strategic Human Resource Management. 4th Edn., Thomas Nelson, South Melbourne, ISBN: 0170104672, pp: 690.

[13] Olugu, E.U. and K.Y. Wong, 2009. Supply chain performance evaluation: trends and challenges. Am. J. Eng. Applied Sci., p.202211.

[14] Sheldon, K.M., A.J. Elliot, Y. Kim and T. Kasser, 2001. What is satisfying about satisfying events? Testing 10 candidate psychological needs. J. Person. Soc. Psychol., 80: 325-339. PMID: 11220449

[15] Basu, S. and S.K. Datta, 2010. The success story of voluntary retirement scheme in national carbon company: a unit of Eveready Industries India Ltd. Am. J. Econ. Bus. Admin., p.157-159.

[16] Spychalsky, A.C., M.A. Quinones, B.B. Gaugler and K. Pohley, 1997. A survey of assessment center practices in organizations in the United States. Person. Psychol., p. 71-90. 